\title{
Therapeutic neutralization of CD95-ligand and TNF attenuates brain damage in stroke
}

\author{
A Martin-Villalba ${ }^{*, 1,2}$, M Hahne $^{4}$, S Kleber ${ }^{2}$, J Vogel ${ }^{2}$, W Falk ${ }^{3}$, \\ $\mathrm{J} \mathrm{Schenkel}^{2}$ and PH Krammer ${ }^{1}$ \\ 1 Tumorimmunology Programm, German Cancer Research Center (DKFZ), \\ Heidelberg, Germany \\ 2 Department of Physiology, University of Heidelberg, Heidelberg, Germany \\ 3 Department of Internal Medicine I, University of Regensburg, Regensburg, \\ Germany \\ ${ }^{4}$ Department of Immunology, National Center of Biotechnology, Madrid \\ * Corresponding author: A Martin-Villalba, German Cancer Research Center \\ (DKFZ), Im Neuenheimer Feld 280, 69120 Heidelberg, Germany. Tel: +49 6221 \\ 423766; Fax: +49 6221 411715; E-mail: c50@ix.urz.uni-heidelberg.de
}

Received 9.3.01; revised 22.3.01; accepted 27.3.01

Edited by G Melino

\begin{abstract}
Stroke is the third most common cause of death in the Western world. The mechanisms of brain damage in the affected areas are largely unknown. Hence, rational treatment strategies are limited. Previous experimental evidence suggested that cerebral lesions were less prominent in CD95 (APO-1/Fas)deficient (Ipr) than in wild-type mice. Additional results strongly suggested that the CD95-ligand (CD95L) was a major cause of neuronal autocrine suicide in the penumbra. These data and the assumption that death-receptor systems might determine stroke-related damage in the brain prompted us to examine these systems in in vitro and in vivo models of ischemia. We showed that hybrids of TNF-deficient and gld mice were strongly resistant towards stroke-induced damage. To determine the mechanism of action of TNF and CD95L, we separately investigated their influence on primary ischemic death and secondary inflammatory injury. Inhibition of both TNF and CD95L in vitro prevented death of primary neurons induced by oxygen-glucose deprivation and reperfusion. The recruitment of inflammatory cells to the ischemic hemisphere was abrogated in the absence of both TNF and CD95L. Significantly, mice injected with a mixture of neutralizing antiTNF and anti-CD95L antibodies $30 \mathrm{~min}$ after induction of stroke showed a marked decrease in both infarct volumes and mortality. Accordingly, the locomotor performance of these animals was not significantly impaired in comparison to shamoperated animals. These data reveal that inhibition of TNF and CD95L blocks stroke-related damage at two levels, the primary ischemic and the secondary inflammatory injury. These results offer new approaches in stroke treatment. Cell Death and Differentiation (2001) 8, 679-686.
\end{abstract}

Keywords: CD95-ligand; TNF; stroke; apoptosis; stroke therapy; gld; thf-ko
Abbreviations: CD95L, CD95-ligand; MCA, middle cerebral artery; TNF, tumor necrosis factor- $\alpha$

\section{Introduction}

Stroke is the third most common cause of death in the Western world and the most important single cause of severe disability. ${ }^{1}$ Current data show that there is a variable therapeutic window that may exceed 6-8 h. ${ }^{2}$ This interval is determined by formation of the ischemic penumbra. Evidence has accumulated that neurons in the ischemic penumbra undergo apoptosis. ${ }^{3}$ Thus, neuroprotective strategies towards suppression of apoptosis may alleviate disease severity in stroke patients.

Tumor necrosis factor-receptor-1 (TNFR1, p55, CD120a) and CD95 (APO-1, Fas) are members of the TNF-R superfamily involved in triggering apoptosis. ${ }^{4-6}$ Like other death receptors, they show a homologous cytoplasmic sequence crucial for the transduction of the apoptotic signal, the 'death domain'.7 Their natural ligands, CD95ligand (CD95L) and TNF are structurally related type II transmembrane proteins. Ligation of receptors by trimerized ligands leads to recruitment of the adaptor protein FADD (Fas-associated death domain, MORT1) ${ }^{8}$ and caspase- 8 into a death inducing signaling complex. ${ }^{9}$ Caspase- 8 in the DISC is activated through self-cleavage ${ }^{10}$ and commits the cell to apoptosis by activation of downstream effector caspases. Activation and cleavage of caspase-3 has been detected in the postischemic brain, ${ }^{11}$ but controversy exists with regard to the steps upstream of caspase activation.

Following brain ischemia, expression of TNF, CD95L and CD95 is increased in the ischemic penumbra. ${ }^{12-16}$ The role of TNF in ischemic brain injury in vivo, however, is controversial. On the one hand, neutralization of endogenous TNF is reported to reduce infarct volume. ${ }^{17-20}$ On the other hand, mice lacking TNF-receptor-1 (TNF-R1; also called p55) or both TNF-R1 and TNF-R2 (also called p75) showed enhanced ischemic damage. ${ }^{21,22}$ It is consistent with these data that administration of TNF prior to the ischemic insult significantly reduced infarct size. ${ }^{23}$ In contrast, the role of CD95/CD95L in ischemic brain disease seems to be deleterious. Ipr mice, lacking functional CD95, exhibited a profound reduction of infarct size. ${ }^{14}$ In addition, in microglia, TNF facilitates CD95Linduced apoptosis. ${ }^{24}$ Whether these two ligand/receptor systems cooperate or counteract each other in the induction of ischemic damage remains unclear.

In the present study we show that mice deficient for TNF $\left(t n f^{-l-}\right)$ or functional CD95L (gld) are protected against brain ischemia. This protection is greatly enhanced in mice lacking both ligand/receptor systems ( $g / d /$ tnf $\left.^{-/-}\right)$. Most importantly, treatment of wild-type mice after induction of ischemia with antibodies against TNF and CD95L 
diminished infarct volumes and significantly improved survival of the animals. Intact functionality of rescued neurons in vivo was demonstrated by an almost normal locomotor performance of the treated animals 3 days after stroke. Thus, simultaneous neutralization of CD95L and TNF may alleviate the consequences of stroke.

\section{Results}

\section{CD95L and TNF induce neuronal death}

To investigate the role of CD95L and TNF in ischemic brain damage, we took advantage of an in vitro model of oxygenglucose deprivation (OGD). OGD in primary neuronal cultures is a common in vitro model for studying early mechanisms of vascular stroke damage in a system mostly consisting of neurons. ${ }^{25}$ Primary cortical neurons were obtained from mice carrying a targeted disruption of the tnf gene $\left(\right.$ tnf $\left.^{-1-}\right),{ }^{26}$ from mice with mutated CD95L and impaired ability to successfully interact with CD95 ( $g / d),{ }^{27}$ from mice deficient in TNF with mutated CD95L ( $\left.\mathrm{gld} / \mathrm{tnf}^{-{ }^{-}}\right)$, and from wild-type mice (wt). Neuronal cultures were then subjected to $6 \mathrm{~h}$ OGD and 3, 18 and $24 \mathrm{~h}$ reperfusion. Whereas the absence of TNF markedly protected against OGD/reperfusion damage, protection due to the absence of a functional CD95L was less profound (Figure 1a). For as yet unknown reasons, despite frequent attempts neuronal cells derived from $\mathrm{gld} / \mathrm{tnf}^{-1-}$ mice could not be grown in culture.

$\mathrm{Tnf}^{-1-}$ and gld mice exhibit normal development and anatomy of the brain. This apparently normal 'cerebralphenotype' may be due to compensatory mechanisms, which might non-specifically protect against brain ischemia. To exclude this possibility, wild-type neurons were treated with CD95-Fc or TNF-R2-Fc proteins $15 \mathrm{~min}$ prior to induction of OGD. Administration of both CD95-Fc and TNF-R2-Fc had toxic effects for the cultures, as it has also been the experience of other groups. After $6 \mathrm{~h}$ of OGD and $18 \mathrm{~h}$ reperfusion scavenging of either CD95L or TNF- $\alpha$ reduced neurotoxicity of the cultures by 55 and $80 \%$, respectively, compared to $\lg \mathrm{G} 1$ (immunoglobulin $\mathrm{G}_{1}$ ) treated controls (Figure 1b). Therefore, inhibition of TNF and CD95L activity can specifically block OGD/reperfusioninduced neuronal death.

\section{CD95L and TNF synergistically promote cell death following brain ischemia}

To examine the in vivo role of TNF and CD95L and their possible interaction in ischemic brain damage we used tnf $^{-/-}$, gld, gld/thf ${ }^{-1-}$, and wild-type mice (wt), all on C57BL/6 background. gld/tnf ${ }^{-1-}$ mice showed no structural or morphological abnormalities of the brain as assessed by Nissl staining of coronal cryostat sections (data not shown).

wt, gld, tnf $^{-1-}$ and $\mathrm{gld} / \mathrm{tnf}^{-1-}$ mice underwent $90 \mathrm{~min}$ occlusion of the middle cerebral artery (MCA) and $24 \mathrm{~h}$ reperfusion. Physiological parameters such as blood pressure, blood $\mathrm{pH}, \mathrm{pO}_{2}, \mathrm{pCO}_{2}$ and glucose measured before, during and after MCA occlusion did not significantly differ between the different animal groups (data not shown).
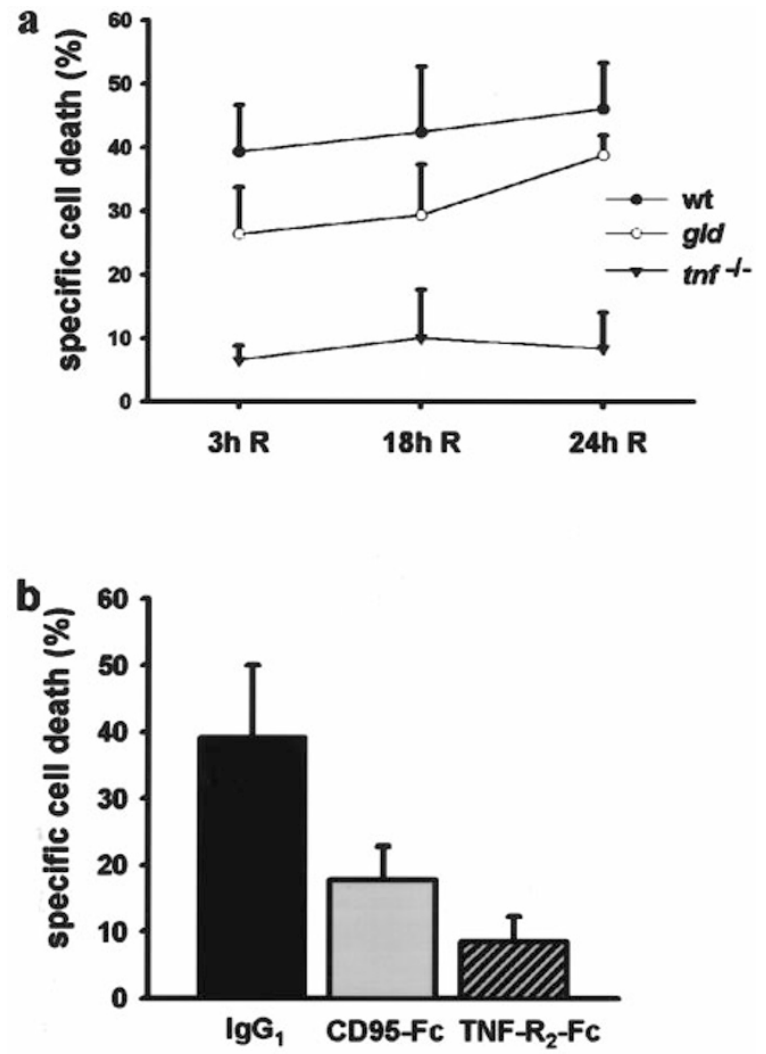

Figure 1 Protection against ischemic death in an in vitro model of vascular stroke. (a) Cortical neurons from wild-type, gld and tnf $^{-1-}$ mice were subjected to $6 \mathrm{~h}$ of oxygen-glucose deprivation (OGD) and increasing reperfusion periods $(R)$. Specific death was assessed at 3,18 and $24 \mathrm{~h}$ of reperfusion $(R)$. (b) Cortical neurons from wild-type animals were incubated with CD95-Fc and TNF-R2-Fc proteins $(20 \mu \mathrm{g} / \mathrm{ml}$ each) prior to induction of $6 \mathrm{~h}$ OGD and $18 \mathrm{~h}$ of reperfusion; specific death was assessed at the end of the reperfusion period. Incubation with control immunoglobulin $\left(\operatorname{lgG}_{1}\right)$ did not have any effect on neurotoxicity of the cultures. Cell death was assessed by trypanblue exclusion and given as the means \pm S.D. $(n=3)$. Differences between per cent of cell death in wt and gld and $t n f^{-I_{-}}$animals were statistically significant $(P<0.05$ and $P<0.00009$, respectively). The same applied to the treated groups: IgG1 and CD95-Fc and TNF-R2-Fc treated cells $(P<0.009$ and $P<0.0001$, respectively) as assessed by student $t$-test

The mean infarct volume exhibited by wt-animals was in good concordance with that obtained by other groups in similar models. ${ }^{21,28}$ Data from mice which did not exhibit an ischemic lesion (10\% wt, $30 \% \mathrm{gld}$ and $40 \% \mathrm{thf}^{-/-}$and $\mathrm{gld} /$ tnf $^{-1-}$ mice) or from mice who died before the end of the $24 \mathrm{~h}$ observation period (Figure $2 \mathrm{a}$ ) were not included in the analyses of infarct volume.

In gld and tnf $^{-1-}$ mice the infarct volume was significantly reduced by about 54 and $67 \%$, respectively, compared to wt mice $\left(23.23 \pm 4.97 \mathrm{~mm}^{3}, n=8\right.$, and $16.44 \pm 7.24 \mathrm{~mm}^{3}, \quad n=7$, versus $54.66 \pm 6.32 \mathrm{~mm}^{3}, \quad n=9$, respectively, both $P<0.01$; Figure $2 b$ ). Surprisingly, neuroprotection was greatly enhanced by the absence of both CD95L and TNF. gld/tnf ${ }^{-1-}$ mice exhibited a mean infarct volume significantly smaller than wt animals $\left(3.97 \pm 1.52 \mathrm{~mm}^{3}, \quad n=8 ; P<0.0001\right.$; Figure $\left.2 \mathrm{~b}\right)$. TNF and CD95 $\mathrm{L}$ have an additive effect in infarct extension as assessed by two factorial variance analysis. 

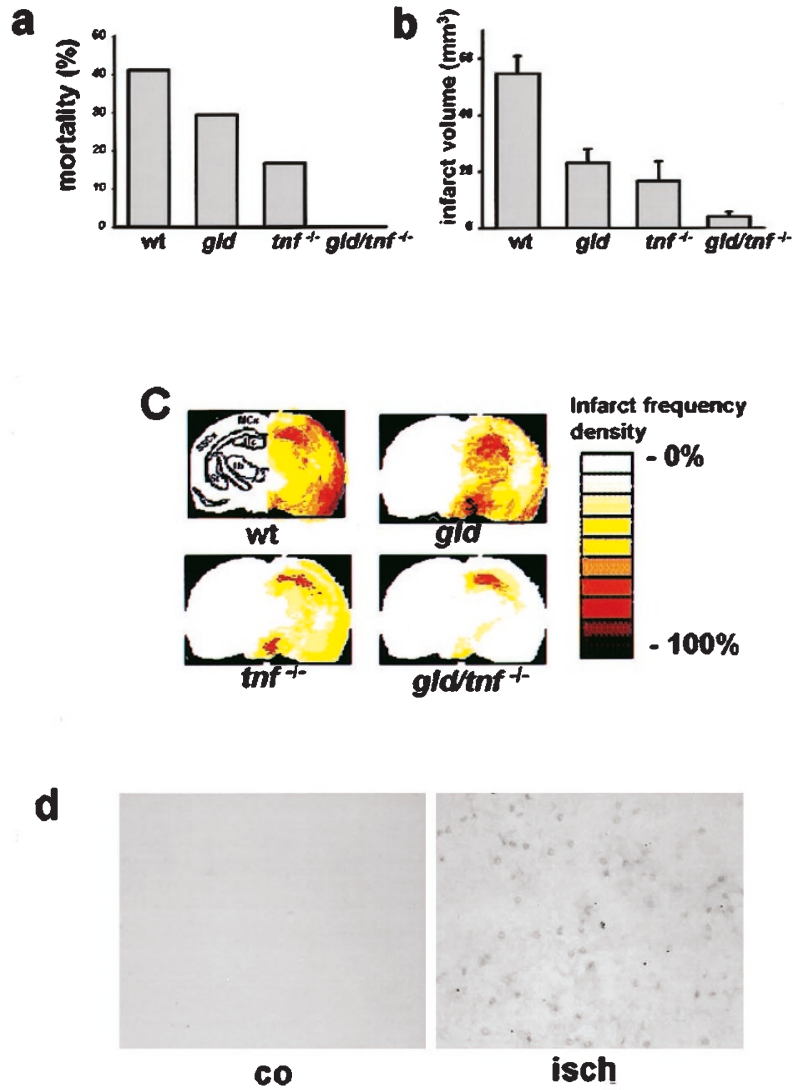

Figure 2 Ischemic brain damage is reduced in $\mathrm{gld}, \mathrm{thf}^{-1-}$ and $\mathrm{gld} / \mathrm{thf}^{-1-}$ mice. (a) mortality within $24 \mathrm{~h}$ after occlusion of the middle cerebral artery (MCA) in wild-type $(n=14)$, gld $(n=17)$, tnf $^{-\prime-}(n=13)$, and gld/thf ${ }^{-\prime-}(n=15)$ mice. (b) Infarct volume after transient focal ischemia in wild-type $(n=9)$, gld $(n=8)$, tnf $^{-1-}(n=7)$, and $g / d /$ tnf $^{-1-}(n=8)$ mice. Animals were subjected to 90 min occlusion of the MCA and $24 \mathrm{~h}$ reperfusion as described. Cryostat coronal sections, $20 \mu \mathrm{m}$ thick and $400 \mu \mathrm{m}$ apart from each other were silverstained. The volume of infarction was determined by numeric integration of areas of marked pallor with section thickness. Data are presented as the means \pm S.E.M. Significance was determined by comparing $\mathrm{gld}_{\mathrm{thf}}{ }^{-1-}$, and $\mathrm{gld} / \mathrm{tnf}^{-1-}$ mice to wild-type mice by using the Mann-Whitneys' U-test $(P<0.01, P<0.01$, and $P<0.0001$, respectively). (c) Image analysis of the regional infarct frequencies of the coronal section at bregma $-2.3 \mathrm{~mm}$ from wild-type, $g l d, t n f^{-\prime-}$, and $g / d / t n f^{-1-}$ mice reveals a relative sparing of the motor and somatosensory cortex and striatum in gld mice and of the entire adjacent neocortex, striatum and thalamus in $\mathrm{tnf}^{-1-}$ mice. In $\mathrm{gld} / \mathrm{tnf}^{-1-}$ mice the hippocampus was almost the only affected area. MCx, motor cortex; SSCx, somatosensory cortex; Hc, hippocampus; Th, thalamus; St, Striatum. (d) Immunohistochemical analysis for CD95L was performed in brain sections from wild-type subjected to $90 \mathrm{~min}$ MCA occlusion and $24 \mathrm{~h}$ reperfusion. CD95L was found in cells in the ischemic penumbra (isch) but not in the corresponding region in the contralateral hemisphere (co)

The regional infarct distribution in the coronal plane was analyzed by averaging infarct areas (coronal section at bregma $-2.3 \mathrm{~mm}$ ). The resulting frequency density map reveals a relative sparing of the motor and somatosensory cortex and striatum in gld mice and a relative sparing of the entire adjacent neocortex, striatum and thalamus in $\operatorname{tnf}^{-1-}$ mice (Figure 2c). In $\mathrm{gld} /$ tnf $^{-1-}$ mice striatum, cortex and thalamus remain unaffected by the ischemic insult and damage is mainly restricted to the hippocampus (Figure 2c).
The spared areas in the $\mathrm{tnf}^{-/-}$and $g / d$ mice belong to the ischemic penumbra - a region surrounding the necrotic core with diminished cerebral blood flow where neurons are at risk of undergoing apoptosis. In these areas TNF has been reported to be expressed in neurons. ${ }^{13}$ With regard to CD95L we already showed expression of this protein in the ischemic penumbra in the rat. ${ }^{14}$ Here we found that in wt mice subjected to $90 \mathrm{~min}$ MCA occlusion and $24 \mathrm{~h}$ reperfusion, $C D 95 \mathrm{~L}$ is expressed in the regions surrounding the necrotic core but not in the corresponding regions in the contralateral hemisphere (Figure 2d). Expression of CD95L was not detectable in the brains of sham-operated animals or in control stainings performed with isotype control IgG or without the first antibody, whereas it was found in tumors transfected with murine-CD95L and in the mouse thymus (data not shown).

\section{CD95L and TNF mediate the recruitment of inflammatory cells following stroke}

In vivo, cytokine production and adhesive events occur early following cerebral blood flow reduction. ${ }^{29} \mathrm{TNF}$, produced by the ischemic parenchyma, contributes to the expression of cellular adhesion molecules of endothelial cells such as, intercellular adhesion molecule-1 (ICAM-1), vascular cell adhesion molecule-1 (VCAM-1) and endothelial-leukocyte adhesion molecule-1 (E-selectin); adhesion molecules facilitate the recruitment of inflammatory cells to the ischemic lesion. Similar chemotactic properties have been described for CD95L in tumors. ${ }^{30,31}$ These data prompted us to ask whether in addition to the death promoting role of CD95L and TNF following ischemia, these two molecules could contribute to the ischemic injury through the recruitment of inflammatory cells. To address this question in brain sections from wt, gld, tnf $^{-1-}$ and $\mathrm{gld} / \mathrm{tnf}^{-1-}$ mice (each $n=3$ ) that underwent focal ischemia (90 min MCA occlusion and $24 \mathrm{~h}$ reperfusion) the number of infiltrating granulocytes and lymphocytes was determined by immunoautoradiography (Figure 3). Control stainings without first antibody or of brain sections from shamoperated animals were negative (data not shown). Quantitative analysis of autoradiograms standardized by infarcted volume, revealed a decreased granulocyte infiltration in tnf $^{-1-}$ and $\mathrm{gld} / \mathrm{tnf}^{-1-}$ mice (Figure 3). The extent of lymphocyte infiltration was similar in wt, in $g l d$ and in tnf $f^{-/-}$ animals and higher in $\mathrm{gld} / \mathrm{tnf}^{-1-}$ mice, possibly due to persistent survival rather than to increased infiltration (Figure 3). These data confirm the chemotactic effect of TNF towards granulocytes following ischemia.

\section{Treatment with anti-TNF and anti-CD95L antibodies reduces ischemic injury}

To find out whether the data obtained from knockout animals can be the basis for therapy, we also investigated the effect of in vivo therapeutic neutralization of TNF and CD95L following focal ischemia in vivo. Wild type mice were i.p. injected with anti-TNF and anti-CD95L antibodies (50 $\mu \mathrm{g}$ each) $30 \mathrm{~min}$ after occlusion of MCA - a time point which would reflect later time points in humans, since the basal metabolic rate in humans is lower than in rodents. ${ }^{32}$ This led to a significant 


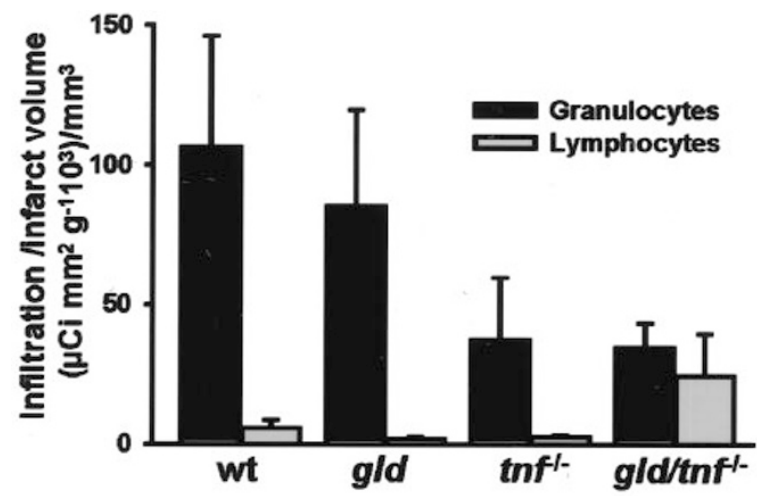

Granulocytes

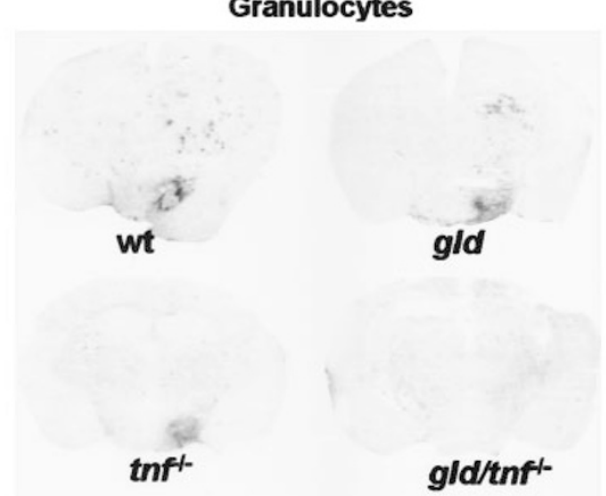

Lymphocytes

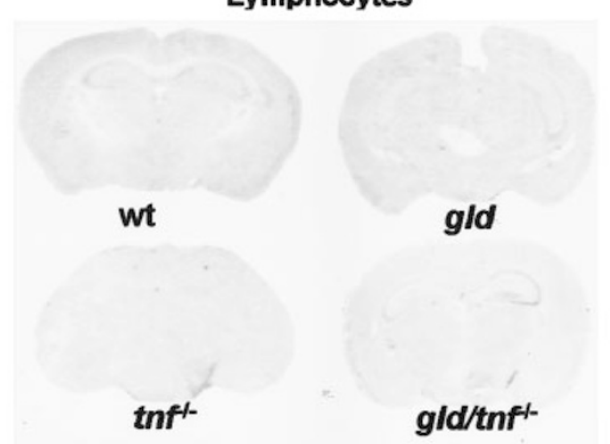

Figure 3 Infiltration by inflammatory cells of the ischemic brain. Infiltration by granulocytes or lymphocytes of the ischemic brains from wild-type, gld, thf $^{-1-}$ and $g / d / t^{\prime \prime} f^{-1}$ mice (each $n=3$ ) was quantified by autoimmunoradiography. Brain sections from brains subjected to focal ischemia ( $90 \mathrm{~min}$ MCA occlusion and $24 \mathrm{~h}$ reperfusion) were incubated with primary antisera against GR1 (for granulocytes) or CD3 (for lymphocytes). Stainings were revealed by autoradiography (representative autoradiography, lower panel). Inflammatory infiltrates in the ischemic hemisphere were quantified by measuring the area and the optical density (OD) of the infiltrates (upper panel) divided by the mean infarct volume of the examined animals. Data are presented as the means \pm S.E.M. $(n=3)$

reduction in the infarct volume by $70 \%$ in double treated compared to saline treated animals $\left(18.04 \pm 4.87 \mathrm{~mm}^{3}, n=5\right.$ in treated mice versus $\mathrm{z} 50.66 \pm 6.32 \mathrm{~mm}^{3}, \quad n=9, \quad P<0.004$; Figure 4a). Inhibition of CD95L and TNF activities had an additive effect in reducing infarct volumes, as assessed by two factorial variance analysis. By contrast, separate inhibition of CD95L or TNF did not significantly reduce infarct volumes. In a second series of experiments was found that

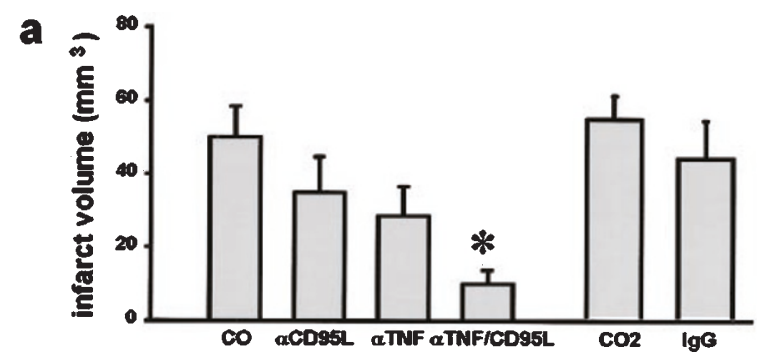

b

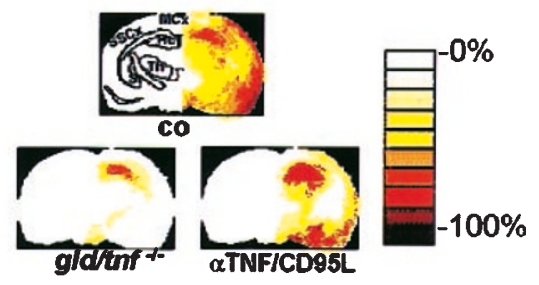

C
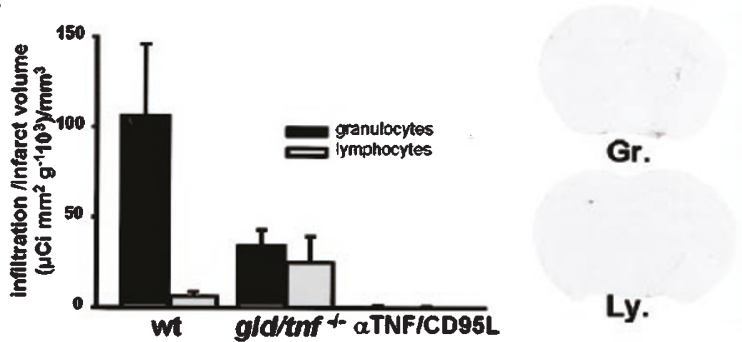

Figure 4 Infarctextension and inflammatory infiltrates of the ischemic brain are significantly reduced by anti-TNF and anti-CD95L antibodies. Wild-type animals subjected to $90 \mathrm{~min}$ MCA occlusion and $24 \mathrm{~h}$ reperfusion were i.p. treated $30 \mathrm{~min}$ after occlusion with saline (co; $n=9)$, or with antibodies against TNF ( $\alpha$ TNF), CD95L ( $\alpha \mathrm{CD} 95 \mathrm{~L}$ ) or both ( $\alpha \mathrm{TNF} / \mathrm{CD} 95 \mathrm{~L})$ ( $n=10$ each group) in a double blind manner. In a second series of experiments animals were either treated with saline (co2; $n=9)$ or IgG (IgG; $n=7)$. Animals who did not exhibit an infarct $(27,40,40,50$ and $10 \%$ of $\mathrm{co}, \alpha \mathrm{TNF}, \alpha \mathrm{CD} 95 \mathrm{~L}$ and $\alpha \mathrm{TNF} / \mathrm{CD} 95 \mathrm{~L}$ and IgG, respectively) or died before the $24 \mathrm{~h}$ period $(33,10,10,30$ and $20 \%$ of co, $\alpha \mathrm{TNF}, \alpha \mathrm{CD} 95 \mathrm{~L}, \mathrm{co} 2$ and $\lg \mathrm{G})$ were not included in the examination of infarct volumes. Cryostat brain coronal section from $20 \mu \mathrm{m}$ thick, $400 \mu \mathrm{m}$ apart from each other, were silver-stained. (a) The volume of infarction was determined by numeric integration of areas of marked pallor with section thickness. Data are presented as the means \pm S.E.M. Significance was determined by comparing saline-treated animals with the other groups by using the Mann-Whitney's test $\left({ }^{*} P<0.004\right)$. (b) Image analysis of the regional infarct frequencies of the coronal section at bregma $-2.3 \mathrm{~mm}$ from co, $\alpha \mathrm{TNF} / \mathrm{CD} 95 \mathrm{~L}$ and $\mathrm{gld} / \mathrm{tnf}^{-1-}$ mice reveals a relative sparing of the motor and somatosensory cortex and striatum in $\alpha \mathrm{TNF} / \mathrm{CD} 95 \mathrm{~L}$-treated mice. MCx, motor cortex; SSCx, somatosensory cortex; Hc, hippocampus; Th, thalamus; St, Striatum. (c) The number of granulocytes and lymphocytes in the ischemic hemisphere were quantified by autoimmunoradiography. Brain sections from animals subjected to focal ischemia ( $90 \mathrm{~min}$ MCA occlusion and $24 \mathrm{~h}$ reperfusion) were incubated with primary antibodies against GR1 (for granulocytes) and CD3 (for lymphocytes). Stainings were revealed by autoradiography (representative autoradiography, right panel). Inflammatory infiltrates in the ischemic hemisphere were quantified by measuring the area and the optical density (OD) of the infiltrates (left panel) divided by the mean infarct volume of the examined animals. Data are presented as the means \pm S.E.M. $(n=3)$

the injection of control IgG did not influence infarct volumes when compared to saline-treated animals (Figure 4a). 
The regional infarct distribution in the coronal plane of anti-TNF/CD95L-treated animals was analyzed by averaging infarct areas (at the coronal level bregma $-2.3 \mathrm{~mm}$ ). The resulting frequency density map shows a sparing of the motor cortex, the lateral thalamic nuclei and the striatum (Figure 4b). Also, in these animals, inflammatory infiltrates were nearly undetectable (Figure 4c).

The functionality of rescued neurons was examined by testing the motor coordination of treated mice 3 days after reperfusion. Thus, anti-TNF and anti-CD95L antibodies (50 $\mu \mathrm{g}$ each) were injected twice i.p. $30 \mathrm{~min}$ and $24 \mathrm{~h}$ after occlusion of MCA. All mice in which focal ischemia was induced and that were not antibody-treated died before the end of the observation period $(n=5)$, whereas mortality in the treated group $(n=10)$ was only $30 \%$ (Figure $5 a$ ). Six non-treated sham-operated animals (so-utr) and five anti-TNF/CD95L-treated mice which underwent $90 \mathrm{~min}$ occlusion of MCA and 3 day reperfusion were tested on a rotarod and on stationary rods. Retention times on the rotarod displayed by treated animals did not significantly differ from those exhibited by sham-operated animals (Figure 5b). Motor coordination on stationary rods paralleled these results (data not shown). Likewise, maintenance of axial balance, as assessed by the first swimming experience of the mice, was comparable in untreated sham-operated and stroketreated animals (data not shown). Even animals with low retention time on the rotarod exhibited unimpaired axial balance.
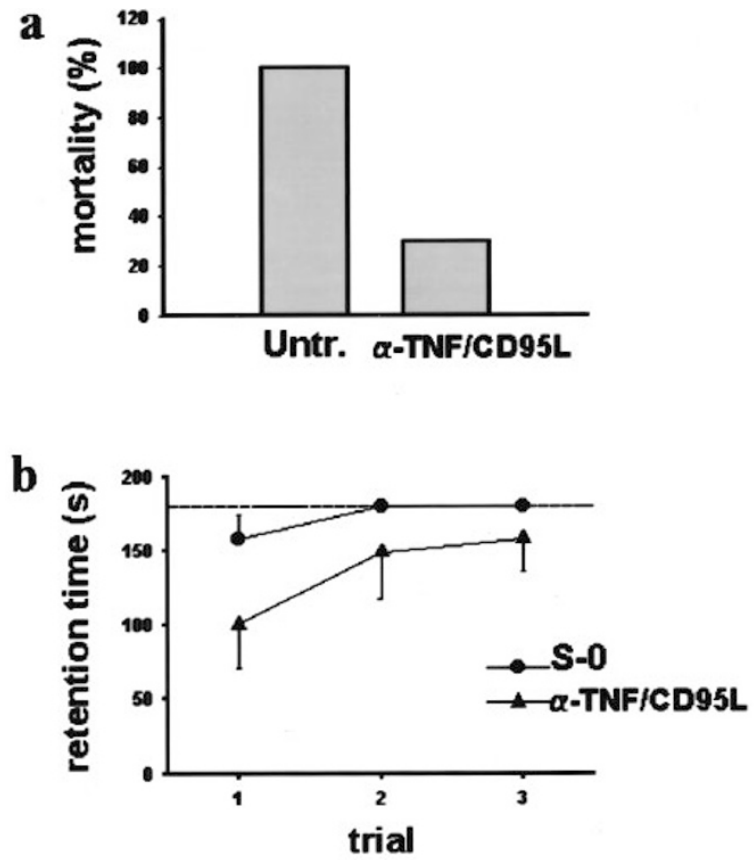

Figure 5 Neutralization of CD95L and TNF reduces mortality and improves motor performance of stroke animals. (a) Percentage of mortality within 3 days after occlusion of the MCA in animals untreated $(n=5$; wt) or treated with antiTNF and anti-CD95L antibodies ( $n=10 ; \alpha$-TNF/CD95L). (b) Retention times on accelerated rotarod for untreated sham-operated animals $(s-0 ; n=6)$ and treated animals $(\alpha-\mathrm{TNF} / \mathrm{CD} 95 \mathrm{~L} ; n=5)$

\section{Discussion}

In this study we report that TNF and CD95L additively contribute to ischemic damage, both by triggering ischemic cell death and by recruiting inflammatory cells to the site of the lesion. Moreover, the therapeutic neutralization of these ligands leads to preservation of neuron functionality and increased survival of the animals.

\section{CD95-L and TNF additively induce ischemic brain damage}

The protection provided by the absence of TNF disagrees with the report by Bruce et al. (1996) of an enhanced ischemic damage in mice lacking TNF-receptor-1 (TNF-R1; also called p55) or both TNF-R1 and TNF-R2 (also called p75). Something that might be due to the use of a different mouse strain $(\mathrm{C} 57 \mathrm{BL} / 6 \times 129)$ and a shorter occlusion time of $1 \mathrm{~h}$ by this group.

In previous studies we have shown that apoptotic cells in the penumbra are mostly neurons and express CD95L. ${ }^{14}$ Here, we report that CD95L is also generated in the ischemic penumbra in the mouse (Figure 2). Expression of TNF mRNA and protein already occurs within $2 \mathrm{~h}$ after induction of ischemia ${ }^{12,13,33,34}$ and is followed by the expression of CD95L at 12 h. $^{14}$ CD95L expression may be induced by TNF, e.g. through transcription factors such as C-Jun or NF$\kappa \mathrm{B},{ }^{35,36}$ like it has been described in human astrocytes. ${ }^{37}$ Thus, these two ligands, TNF and CD95L might compliment each other in the induction of stroke damage. Nevertheless, the fact that neurons from $\mathrm{gld} / \mathrm{tnf}^{-1-}$ could not be cultured in vitro, indicate that these ligand might have other functions in neurons besides the triggering of the death program that should be elucidated in further studies.

The deleterious effect of the CD95 and the TNF system may indeed be related to effects not directed to neurons themselves but to other cells such as microglia, which would in turn produce killer chemokines, ${ }^{38}$ or leucocytes. In support of this idea is recent work which shows that inhibition of caspase-1 induces long-lasting neuroprotection in cerebral ischemia by reducing apoptosis and proinflammatory cytokines. ${ }^{39}$ Nevertheless, the decrease in cell death in vitro in primary neurons in the absence of a functional CD95 or TNF system suggests a harmful role of these systems, at least in part, directed to neurons. Besides, one could argue that the dramatic protection exhibited by $\mathrm{gld} / \mathrm{tnf}^{-1-}$ mice is due to a primary defect in the glia/neuron interaction arising from the mutation in the CD95L and the TNF ligands. This is excluded by the enhanced neuroprotection also achieved by the acute therapeutic neutralization of both CD95 and TNF systems in wild-type animals.

Analysis of infarct frequencies in the coronal plane in gld/thf ${ }^{-1-}$ mice (Figure $1 \mathrm{c}$ ) reveals that hippocampus was almost the only affected area. Hippocampus is the most vulnerable brain area following ischemia possibly due to its higher density of glutamate receptors. Prominent glutamate stimulation through the ischemic insult can favor severe excitotoxicity in which CD95 and TNF systems may play a minor role. 


\section{CD95L and TNF promote inflammation in the ischemic brain}

Ischemia-mediated breakdown of the blood-brain barrier $(\mathrm{BBB})^{40-42}$ leads to the unique exposure of relatively sequestered CNS antigens to the peripheral circulation. This results in a deleterious immune response that enhances neuronal damage ${ }^{43}$ and underlies the transition from ischemic to inflammatory injury. Among inflammatory cells, granulocytes invade the infarct and its boundary zone within hours with a peak at $24 \mathrm{~h}$, whereas T cells start infiltrating the infarct region from day 1 onwards, with a peak around day $7 .^{44}$ Granulocyte infiltration is preceded by an increased expression of cytokine-induced neutrophil chemoattractant (CINC). ${ }^{44}$ Accordingly, at $24 \mathrm{~h}$ after MCA occlusion, we detected inflammatory infiltration with a nearly exclusive participation of granulocytes in the ischemic hemisphere. This infiltration could be reduced in the absence of TNF and/or CD95L, consistent with the known chemotactic properties of these two ligands. ${ }^{30,31,45}$ The recruitment of inflammatory cells to the site of the lesion, like the induction of ischemic neuronal death in vitro, was more effectively inhibited in the absence of TNF than in the absence of CD95L.

Strikingly, however, infarct volumes in $\mathrm{tnf}^{-1-}$ and $\mathrm{gld}$ mice were not significantly different. This similar outcome might be explained by the additional ability of CD95L to activate the cytotoxic machinery of granulocytes. ${ }^{30,31}$ Thus, CD95L might enhance the induction of inflammatory damage by TNF in stroke.

\section{Possible consequences for the treatment of stroke}

Currently, neuroprotective strategies strive to maintain viability of ischemic neurons until reperfusion can be normally re-established. However, cerebral reperfusion is followed by destruction of microvasculature and subsequent inflammatory events. Therefore, protection towards both reperfusion damage and ischemic death emerges as the ideal therapy for stroke either in combination with thrombolytic therapy or alone if thrombolysis is precluded.

In the microcirculatory failure and the inflammatory events that follow reperfusion different effectors participate, such as the intercellular adhesion molecule-1 (ICAM1) or CD18 (the beta2-integrin subunit on granulocytes and ligand for ICAM-1). The absence of ICAM-1 or CD18 mitigates stroke damage by improving microcirculation in the ischemic penumbra. ${ }^{46,47}$ Moreover, in ICAM-1 knockout animals, further granulocyte depletion enhances protection. ${ }^{46}$ Interestingly, ICAM-1 expression in the ischemic brain is enhanced by TNF. ${ }^{20}$ Early studies in a rabbit model of acute stroke indicated the potential of the combination of thrombolytic therapy with anti-ICAM-1 antibodies. ${ }^{48}$ In comparison, neutralization of TNF and CD95L, not only attenuates reperfusion damage but also helps to maintain neuronal viability until reperfusion is achieved.

Apoptotic cell death and inflammation are also important components of the pathophysiology of other acute and chronic neurodegenerative diseases such as Parkinson's, Alzheimer's and Prion diseases, HIV encephalopathy, and multiple sclerosis. Therefore, the therapeutical neutraliza- tion of CD95L and TNF might have a more global application in acute neurodestruction as well as in chronic neurodegenerative diseases.

\section{Materials and Methods}

\section{Cell culture and experimental treatment in vitro}

Primary neuronal cultures were prepared from day 15 to 17 fetal mice as previously described. ${ }^{14}$ In brief, cortical neurons were obtained after trituration in MEM medium with $20 \%$ horse serum, $25 \mathrm{mM}$ glucose and $2 \mathrm{mM}$ L-glutamine (all from Gibco/Life Technologies, Scotland) following a 30 min digestion in 0.025 trypsin/saline solution. Cells were plated in 24 well plates coated with polyornithine (Sigma, Germany). After 4 days, cells were treated with cytosine-arabinoside $(5 \mu \mathrm{M})$ for another 4 days to inhibit proliferation of non-neuronal cells. Thereafter, cell cultures were maintained in MEM, $10 \%$ horse serum, $5 \%$ fetal bovine serum, $25 \mathrm{mM}$ glucose and $2 \mathrm{mM} \mathrm{L}$-glutamine in a $8 \%$ $\mathrm{CO}_{2}$ humidified incubator at $37^{\circ} \mathrm{C}$. Neurons were allowed to mature for at least 8 days in culture before being used for experiments. The proportion of glial cells in the cultures was less than $10 \%$, as assessed by an antibody against glial-fibrillary-acidic protein (GFAP; data not shown).

\section{Oxygen-glucose deprivation in vitro}

Combined oxygen-glucose deprivation (OGD) was performed as previously described ${ }^{25}$ with minor modifications. The culture medium was replaced with MEM, $1 \%$ horse serum and $2 \mathrm{mM} \mathrm{L-glutamine.} \mathrm{The}$ cultures were kept in an anaerobic chamber for $6 \mathrm{~h}$ containing the gas mixture, $5 \% \mathrm{H}_{2} / 90 \% \mathrm{~N}_{2} / 5 \% \mathrm{CO}_{2}$, and GasPak Catalyst replacement charges (Becton Dickinson, Germany), maintained at $37^{\circ} \mathrm{C}$ and $100 \%$ humidity. Combined oxygen-glucose deprivation was terminated by removal of the cultures from the chamber and adding horse and fetal bovine serum and glucose to a final concentration of $10 \%, 5 \%$ and $25 \mathrm{mM}$, respectively. The cultures were returned to a humidified incubator containing $8 \% \mathrm{CO}_{2}$ and atmospheric oxygen at $37^{\circ} \mathrm{C}$ for another 3, 18 or 24 h. Human IgG1 (Sigma, Deisenhofen, Germany), CD95-Fc and TNF-R2-Fc (20 $\mu \mathrm{g} / \mathrm{ml}$ each) were added to the culture medium 5 min prior to the induction of OGD.

Due to the impossibility to analyze cell death in primary neurons by forward side scatter analysis (FACS) the percentage of cell death was assessed by Trypan-blue exclusion and given as $\%$ of specific death. This was calculated as follows:

$$
\% \text { specific death }=\frac{(\text { assessed death spontaneous death })}{(100 \text { spontaneous death })} \times 100
$$

Spontaneous cell death was of $12 \% \pm 0.09$ for neurons from tnf ${ }^{-1-}$ mice, $10 \% \pm 0.73$ for neurons from gld mice and of $15 \% \pm 0.87$ for neurons from C57BL/6 wild-type mice. All data are given as the means \pm S.D. $(n=3)$.

\section{Ischemic animal model}

In wild-type, gld, tnf $^{-1-}$ and $g / d /$ tnf $^{-/-}$mice, all matched for age (mean 100 days) and weight (mean $24 \mathrm{~g}$ ), focal cerebral ischemia was induced by occlusion of the middle cerebral artery (MCA) as described previously. ${ }^{14}$ A surgical nylon thread was advanced from the lumen of the common carotid artery up to the anterior cerebral artery to block the origin of the MCA for $90 \mathrm{~min}$. MCA blood flow was restored by withdrawing the nylon thread. Deep anesthesia was reached by 
Ketamin and Rompun (150 mg/kg body weight each). Animals were kept under anesthesia and rectal temperature was controlled at or near $37^{\circ} \mathrm{C}$ with a Heating lamp throughout both the surgical procedure and the MCA occlusion period up to the time the animals recovered from anesthesia. A reduction of cerebral blood flow in the animals included in the study was indirectly confirmed by a reduction in the silver infarct staining intensity. ${ }^{49}$ After different reperfusion periods animals were deeply reanesthetized and killed by decapitation. To obtain physiological parameters, the right femoral artery was cannulated under ongoing anesthesia, blood pressure continually recorded, and samples for blood gas and glucose analysis taken $15 \mathrm{~min}$ before, $1 \mathrm{~h}$ after begin and 30 min after the end of MCA occlusion. Mice gender varied due to the availability in our animal facilities. Infarct outcome was not influenced by the sex of the animal (data not shown). All mice were on a C57BL/ 6 background to avoid known differences in infarct susceptibility dependent on the mice strain. ${ }^{50}$

For treatment experiments, anti-CD95L antibody (MFL3; Pharmingen, Germany) and anti-TNF antibody (V1q) ${ }^{51} 50 \mu$ g each, were either i.p. injected $30 \mathrm{~min}$ and $24 \mathrm{~h}$ after occlusion of the MCA in 12-weekold male C57BL/6 in a double blind manner. In a second series of experiments mice were i.p. treated with saline or control hamster IgG (Pharmingen).

\section{Measurement of infarct extension}

Mice were subjected to MCA filament occlusion for $90 \mathrm{~min}$ and reperfused for $24 \mathrm{~h}$ as described. The time point of $24 \mathrm{~h}$ was chosen for reasons of practicability (number of animals and amounts of purified proteins used) and because at this time the major damage has already taken place and infarct volumes do not significantly differ from those thereafter. Forebrains were cut and cryostat coronal sections $20 \mu \mathrm{m}$ thick $400 \mu \mathrm{m}$ apart from each other, were silver-stained. In brief, sections were impregnated with a silvernitrate/lithiumcarbonate solution for $2 \mathrm{~min}$ and developed with a hydrochinone/formaldehyde solution for 3 min. ${ }^{49}$ Stained sections were directly scanned (MCIDM4, 3.0; Imaging res. Inc.). The volume of infarction was determined by numeric integration of the scanned areas of marked pallor corrected for brain edema $x$ section thickness using digital planimetry. All data are given as mean \pm standard error of the mean. Significance was measured using the Mann-Whitney $U$-test. To generate infarct frequency distribution maps, ${ }^{52}$ the respective sections of each series were scanned, infarcts delineated, and projected on a mask. Averaging was done with Scion Image $\beta$ 3.b.

\section{Immunohistochemical analysis of CD95L and TNF expression}

Coronal cryostat sections $(20 \mu \mathrm{m})$ from wild type mice that underwent $90 \mathrm{~min}$ MCA occlusion and $24 \mathrm{~h}$ reperfusion were processed for immunohistochemistry. Sections were incubated with a polyclonal antibody against CD95L (P62). ${ }^{53}$ Immunoreactivity of CD95L protein was visualized by diaminobenzidine (Alexis, Germany). Neither CD95L nor TNF were detectable in the brains of sham-operated animals or in control stainings performed without the first antibody or isotype control $\operatorname{lgG}$, whereas it was detectable in the mouse thymus and in sections from tumors transfected with murine-CD95L (data not shown).

\section{Detection of infiltration of inflammatory cells}

Coronal cryostat sections $(20 \mu \mathrm{m})$ from wt, $\mathrm{gld}$ thf $^{-1-}$ and $\mathrm{gld} / \mathrm{thf}^{-1-}$ mice that underwent $90 \mathrm{~min}$ MCA occlusion and $24 \mathrm{~h}$ reperfusion were processed for immunoautoradiography. Sections were incubated for $24 \mathrm{~h}$ with a monoclonal antibody against GR1 (Ly-1, Pharmingen, Germany) or a monoclonal antibody against CD3 (Chemicon, USA). Thereafter, sections were incubated with a ${ }^{125}$ I-labeled secondary antibody (Biotrend, Germany). Sections were exposed together with a $\left[{ }^{125}\right]$ standard set on a Kodak MinR1 x-ray film for 21 days. Granulocyte or lymphocyte infiltration in the ischemic hemisphere was assessed by measuring the optical density and the area of the infiltrates with an image analyzing system (MCID, Imaging Research Inc., Ontario, Canada).

\section{Motor coordination}

Male C57BL/6 mice 12-16-week-old were placed on a fixed horizontal wood rod or a plexiglass rod $(1 \mathrm{~cm}$ diameter, $50 \mathrm{~cm}$ length, and $40 \mathrm{~cm}$ above ground), and the time the animal remained on the rod was measured. For the rotarod examination (Ugo Basile Biol. Res. App.), the mouse was placed on a gritted plastic roller, which was accelerated from 4 to 40 r.p.m. in 5 min. Retention times were recorded for $180 \mathrm{~s}$.

\section{Acknowledgements}

TNF k.o. mice were kindly provided by M Mike. This work was supported by a grant of the University of Heidelberg to A Martin-Villalba.

\section{References}

1. Poungvarin N (1998) Stroke in the developing world. Lancet 352: 19-22

2. Ginsberg MD (1995) The concept of the therapeutic window: a synthesis of critical issues. In: Moskowitz MA, Caplan LR, eds. (Cerebrovascular disease. 19th Princetown Stroke Conference. Newton: Butterworth Heinemann), pp.331-352

3. Linnik MD, Zobrist RH and Hatfield MD (1993) Evidence supporting a role for programmed cell death in focal cerebral ischemia in rats. Stroke 24:2002-2008

4. Itoh N and Nagata S (1993) A novel protein domain required for apoptosis. J. Biol. Chem. 268: $10932-10937$

5. Oehm A, Behrmann I, Falk W, Pawlita M, Maier G, Klas C, Li-Weber M, Richards S, Dhein J, Trauth BC, Martin-Villalba A, Hahne M, Kleber S, Vogel J, Schenkel J and Krammer PH. (1992) Purification and molecular cloning of the APO-1 cell surface antigen, a member of the tumor necrosis factor/nerve growth factor receptor superfamily. Sequence identity with the Fas antigen. J. Biol. Chem. 267: $10709-10715$

6. Smith CA, Davis T, Anderson D, Solam L, Beckmann MP, Jerzy R, Dower SK, Cosman D and Goodwin RG (1990) A receptor for tumor necrosis factor defines an unusual family of cellular and viral proteins. Science 248: 1019-1023

7. Tartaglia LA, Ayres TM, Wong GH and Goeddel DV (1993) A novel domain within the $55 \mathrm{kd}$ TNF receptor signals cell death. Cell 74: 845-853

8. Kischkel FC, Hellbardt S, Behrmann I, Germer M, Pawlita M, Krammer PH and Peter ME (1995) Cytotoxicity-dependent APO-1 (Fas/CD95)-associated proteins form a death-inducing signaling complex (DISC) with the receptor. EMBO J. 14: 5579-5588

9. Medema JP, Scaffidi C, Kischkel FC, Shevchenko A, Mann M, Krammer PH and Peter ME (1997) FLICE is activated by association with the CD95 death-inducing signaling complex (DISC). EMBO J. 16: 2794-2804

10. Scaffidi C, Fulda S, Srinivasan A, Friesen C, Li F, Tomaselli KJ, Debatin KM, Krammer PH and Peter ME (1998) Two CD95 (APO-1/Fas) signaling pathways. EMBO J. 17: 1675-1687

11. Namura S, Zhu J, Fink K, Endres M, Srinivasan A, Tomaselli KJ, Yuan J and Moskowitz MA (1998) Activation and cleavage of caspase-3 in apoptosis induced by experimental cerebral ischemia. J. Neurosci. 18: 3659-3668 
12. Buttini M, Appel K, Sauter A, Gebicke-Haerter PJ and Boddeke HW (1996) Expression of tumor necrosis factor apha after focal cerebral ischemia in the rat. Neuroscience 71: 1-16

13. Liu T, Clark RK, McDonnell PC, Young PR, White RF, Barone FC and Feuerstein GZ (1994) Tumor necrosis factor $\alpha$ expression in ischemic neurons. Stroke 25: $1481-1488$

14. Martin-Villalba A, Herr I, Jeremias I, Hahne M, Brandt R, Vogel J, Schenkel J, Herdegen T and Debatin KM (1999) CD95 ligand (Fas-L/APO-1L) and tumor necrosis factor-related apoptosis-inducing ligand mediate ischemia-induced apoptosis in neurons. J. Neurosci. 19: 3809-3817

15. Matsuyama T, Hata R, Yamamoto $Y$, Tagaya $M$, Akita $H$, Uno $H$, Wanaka A Furuyama $J$ and Sugita $M(1995)$ Localization of Fas antigen mRNA induced in postischemic murine forebrain by in situ hybridization. Mol. Brain Res. 34: 166 172

16. Saito K, Suyama K, Nishida K, Sei Y and Basile AS (1996) Early increases in TNF-alpha, IL-6 and IL-1 beta levels following transient cerebral ischemia in gerbil brain. Neurosci. Lett. 206: 149-152

17. Nawashiro H, Martin D and HallenbeckJM (1997) Neuroprotective effects of TNF binding protein in focal cerebral ischemia. Brain Res. 778: 265-271

18. Meistrell ME, Botchkina GJ, Wang H, Di Santo E, Cockroft KM, Bloom O, Vishnubhakat JM, Ghezzi P and Tracey KJ (1997) Tumor necrosis factor is a brain damaging cytokine in cerebral ischemia. Shock 8: $341-348$

19. Barone FC, Arvin B, White RF, Miller A, Webb CL, Willette RN, Lysko PG and Feuerstein GZ (1997) Tumor necrosis factor-alpha. A mediator of focal ischemic brain injury. Stroke 28: 1233-1244

20. Yang GY, Gong C, Qin Z, Ye W, Mao Y and Bertz AL (1998) Inhibition of TNF $\alpha$ attenuates infarct volume and ICAM-1 expression in ischemic mouse brain NeuroReprot 9: 2131-2134

21. Bruce AJ, Boling W, Kindy MS, Peschon J, KraemerPJ, CarpenterMK, Holtsberg FW and Mattson MP (1996) Altered neuronal and microglial responses to excitotoxic and ischemic brain injury in mice lacking TNF receptors. Nat. Med. 2 $788-794$

22. Gary DS, Bruce-Keller AJ, Kindy MS and Mattson MP (1998) Ischemic and excitotoxic brain injury is enhanced in mice lacking the $p 55$ tumor necrosis factor receptor. J. Cereb. Blood Flow Metab. 18: 1283-1287

23. Nawashiro H, Tasaki K, Ruetzler CA and Hallenbeck JM (1997) TNF-alpha pretreatment induces protective effects against focal cerebral ischemia in mice. J. Cereb. Blood Flow Metab. 17: 483-490

24. Spanaus KS, Schlapbach R and Fontana A (1998) TNF-alpha and IFN-gamma render microglia sensitive to Fas ligand-induced apoptosis by induction of Fas expression and down-regulation of Bcl-2 and Bcl-xL. Eur. J. Immunol. 28: 4398 4408

25. Monyer H, Giffard RG, Hartley DM, Dugan LL, Goldberg MP and Choi DW (1992) Oxygen or glucose deprivation-induced neuronal injury in cortical cell cultures is reduced by tetanus toxin. Neuron. 8: 967-973

26. Marino MW, Dunn A, Grail D, Inglese M, Noguchi Y, Richards E, Jungbluth A, Wada H, Moore M, Williamson B, Basu S and Old LJ (1997) Characterization of tumor necrosis factor-deficient mice. Proc. Natl. Acad. Sci. USA 94: 8093-8098

27. Cohen PL and Eisenberg RA (1991) Lpr and gld: single gene models of systemic autoimmunity and lymphoproliferative disease. Annu. Rev. Immunol. 9: 243269

28. Eliasson MJ, Sampei K, Mandir AS, Hurn PD, Traystman RJ, Bao J, Pieper A Wang ZQ, Dawson TM, Snyder SH and Dawson VL (1997) Poly (ADPribose)polymerase gene disruption renders mice resistant to cerebral ischemia. Nature Med. 3: 1089-1095

29. del Zoppo GJ (1997) Microvascular responses to cerebral ischemia/ inflammation. Ann. NY Acad. Sci. 823: 132-147

30. Seino K, Kayagaki N, Okumura Kand Yagita H (1997) Antitumor effect of locally produced CD95 ligand. Nat. Med. 3: $165-170$

31. Chen JJ, Sun Y and Nabel GJ (1998) Regulation of the proinflammatory effects of Fas ligand (CD95L). Science 282: 1714-1717

32. Siesjö BK (1992) Pathophysiology and treatment of focal cerebral ischemia. Part I: Pathophysiology. J. Neurosurg. 77: 169-184

33. Szaflarski J, Burtrum D and Silverstein FS (1995) Cerebral hypoxia-ischemia stimulates cytokine gene expression in perinatal rats. Stroke 26: 1093-1100
34. Feuerstein GZ, Wang X and Barone FC (1997) Inflammatory gene expression in cerebral ischemia and trauma. Potential new therapeutic targets. Ann. NY Acad. Sci. 825: $179-193$

35. Le-Niculescu H, Bonfoco E, Kasuya Y, Claret FX, Green DR and Karin M (1995) Withdrawal of survival factors results in activation of the JNK pathway in neuronal cells leading to Fas ligand induction and cell death. Mol. Cell. Biol. 19: 751-763

36. Li-Weber M, Laur O, Dern K and Krammer PH (2000) T cell activation-induced and HIV tat-enhanced CD95(APO-1/Fas) ligand transcription involves NFkappaB. Eur. J. of Immunology 30: 661-670

37. Choi C, Park J, Lee J, Lim JH, Shin EC, Ahn YS, Kim CH, Kim SJ, Kim JD, Choi IS and Choi IH (1999) Fas ligand and Fas are expressed constitutively in human astrocytes and the expression increases with IL-1, IL-6, TNF-alpha, or IFNgamma. J. Immunol. 162: 1889-1895

38. Kaul M and Lipton SA (1999) Chemokines and activated macrophages in HIV gp120-induced neuronal apoptosis. Proc. Natl. Acad. Sci. USA 96: 8212-8216

39. Rabufetti M, Sciorati C, Tarozzo G, Clementi E, Manfredi AA and Beltramo M (2000) Inhibition of caspase-1-like activity by Ac-Tyr-Val-Ala-Asp-Chloromethyl ketone induces long-lasting neuroprotection in cerebral ischemia through apoptosis reduction and decrease of proinflammatory cytokines. J. Neurosci. 20: 4398-4404

40. Hohlbaum AM, Moe S and Marshak-Rothstein A (2000) Opposing effects of transmembrane and soluble Fas ligand expression on inflammation and tumor cell survival. J. Exp. Med. 191: 1209-1220

41. Dobbin J, Crockard HA and Ross-Russell R (1989) Transient blood-brain barrier permeability following profound temporary global ischaemia: an experimental study using 14C-AIB. J. Cereb. Blood Flow Metab. 9: 71-78

42. Nagahiro S, Goto S, Korematsu K, Sumi M, Takahashi M and Ushio Y (1994) Disruption of the blood-cerebrospinal fluid barrier by transient cerebral ischemia. Brain Res. 633: 305-311

43. Becker KJ, McCarron RM, Ruetzler C, Laban O, Sternberg E, Flanders KC and Hallenbeck JM (1997) Immunologic tolerance to myelin basic protein decreases stroke size after transient focal cerebral ischemia. Proc. Natl. Acad. Sci. USA 94: $10873-10878$

44. Stoll G, Jander S and Schroeter M (1998) Inflammation and glial responses in ischemic brain lesions. Progr. Neurobiol. 56: 149-171

45. Mano-Hirano Y, Sato N, Sawasaki Y, Haranaka K, Satomi N, Nariuchi H and Goto T (1987) Inhibition of tumor-induced migration of bovine capillary endothelial cells by mouse and rabbit tumor necrosis factor. J. Natl. Cancer Inst. 78: 115120

46. Kitagawa K, Matsumoto M, Mabuchi T, Yagita Y, Ohtsuki T, Hori M and Yanagihara T (1998) Deficiency of intercellular adhesion molecule 1 attenuates microcirculatory disturbance and infarction size in focal cerebral ischemia. J. Cereb. Blood Flow Metab. 18: 1336-1345

47. Prestigiacomo CJ, Kim SC, Connolly Jr ES, Liao H, Yan SF and Pinsky DJ (1999) CD18-mediated neutrophil recruitment contributes to the pathogenesis of reperfused but not nonreperfused stroke. Stroke 30: 1110-1117

48. Bowes MP, Rothlein R, Fagan SC and Zivin JA (1995) Monoclonal antibodies preventing leukocyte activation reduce experimental neurologic injury and enhance efficacy of thrombolytic therapy. Neurology 45: 815-819

49. Vogel J, Mobius C and Kuschinsky W (1999) Early delineation of ischemic tissue in rat brain cryosections by high-contrast staining. Stroke 30: 1134-1141

50. Connolly ES, Winfree CJ, Stern DM, Solomon RA and Pinsky DJ (1996) Procedural and strain-related variables significantly affect outcome in a murine model of focal cerebral ischemia. Neurosurgery 38: 523-531

51. Echtenacher B, Falk W, Mannel DN and Krammer PH (1990) Requirement of endogenous tumor necrosis factor/cachectin for recovery from experimental peritonitis. J. Immunol. 145: 3762-3766

52. Schneider A, Martin-Villalba A, Weih F, Vogel J, Wirth T and Schwaninger M (1995) NF-kappaB is activated and promotes cell death in focal cerebral ischemia. Nat. Med. 5: 554-559

53. Hahne M, Rimoldi D, Schroter M, Romero P, SchreierM, French LE, SchneiderP, Bornand T, Fontana A, Lienard D, Cerottini J and Tschopp J (1996) Melanoma cell expression of Fas(Apo-1/CD95) ligand: implications for tumor immune escape. Science 274: 1363-1366 